\title{
FITOTECNIA
}

\section{COMPONENTES DA PRODUÇÃO, PRODUTIVIDADE DE GRÃOS E CARACTERÍSTICAS TECNOLÓGICAS DE CULTIVARES DE FEIJÃo ${ }^{(1)}$}

\author{
EDISON ULISSES RAMOS JUNIOR ${ }^{(2)}$; LEANDRO BORGES LEMOS ${ }^{(3)}$; \\ TIAGO ROQUE BENETOLI DA SILVA ${ }^{(2)}$
}

\begin{abstract}
RESUMO
A utilização de cultivares com elevado potencial produtivo, adaptados ao local de cultivo e de boas características culinárias são de suma importância à cadeia produtiva do feijão. O objetivo deste trabalho foi avaliar o comportamento de cultivares de feijão (Phaseolus vulgaris L.) do grupo comercial carioca, identificando aqueles superiores quanto aos componentes da produção, produtividade de grãos, e às características tecnológicas, na semeadura "das águas" de 2000. O delineamento experimental foi o de blocos ao acaso, com 15 tratamentos, constituídos pelas cultivares: Carioca, Pérola, IAC-Carioca SH, IAC-Carioca Eté, IAC-Carioca Pyatã, Carioca Precoce, IAC-Carioca Aruã, FT-Bonito, Rudá, Aporé, Princesa, IAPAR 14, IAPAR 80, IAPAR 81 e Porto Real, com quatro repetições. A massa de cem grãos e o número de grãos por vagem são os componentes de maior influência na produtividade de grãos de cultivares de feijão. As cultivares Aporé, Carioca Precoce e Rudá, destacam-se com produtividade de grãos acima de $3.500 \mathrm{~kg}$ $h^{-1}$. As características tecnológicas dos grãos das cultivares Carioca, IAPAR 80 e IAPAR 81, são maiores.

Palavras-chave: Phaseolus vulgaris L., rendimento de grãos, componentes agronômicos, tempo para cozimento, proteína bruta, capacidade de hidratação.
\end{abstract}

\section{ABSTRACT \\ YIELDING COMPONENTS AND TECHNOLOGICAL CHARACTERS OF COMMON BEAN CULTIVARS}

High yielding potential and proper cooking characters are the main desirable factors to be taken into account in the choise of new common bean cultivars. In this research work, the yielding components considered were number of pods/plant, number of grains/pod and 100 grain-mass. As to the tecnological characters, grain crude protein content, cooking time and hydration ability were measured. A randomized complete block design, with four replications, was set up in which 15 common bean cultivars were checked for the above mentioned parameters (Carioca, Pérola, IAC Carioca, IAC Carioca Eté, IAC Carioca Pyatã, Carioca Precoce, IAC Carioca Aruã, FT Bonito, Rudá, Aporé, Princesa, IAPAR 14, IAPAR 80, IAPAR 81 and Porto Real). Grain yileding potentials above $3,500 \mathrm{~kg} \mathrm{ha}^{-1}$ were observed in the cultivars Aporé, Carioca Precoce and Rudá with superior cooking parameters being detected in the cultivars Carioca, IAPAR 80 and IAPAR 81.

Key words: Phaseolus vulgaris L., yielding components, cooking time, brute protein, hydration capacity.

\section{INTRODUÇÃO}

( $\left.{ }^{1}\right)$ Recebido para publicação em 23 de outubro de 2003 e aceito em 27 de outubro de 2004.

( $\left.{ }^{2}\right)$ Pós-graduando do Departamento de Produção Vegetal, FCA/UNESP, Caixa Postal 237, 18603-970 Botucatu (SP). e-mail: edison@fca.unesp.br; benetoli@fca.unesp.br

$\left({ }^{3}\right)$ Departamento de Produção Vegetal, FCA/UNESP. e-mail: leandrobl@fca.unesp.br 
Na última década, constatou-se grande evolução na cultura do feijão (Phaseolus vulgaris L.) graças ao desempenho da pesquisa, sendo oferecidas ao produtor rural, técnicas compatíveis aos vários sistemas de produção, destacando-se a obtenção de cultivares com elevado potencial produtivo (ZimMERMANN et al., 1996; YокоYAMA et al., 2000; CARbonell et al., 2003) e adaptados ao local de cultivo (Ramalho et al., 1993; Duarte e Zimmermann, 1994; Piana et al., 1999; Carbonell e Pompeu, 2000; Carbonell et al.; 2001). Associado a tudo isso, o fato de o feijoeiro ser uma planta de ciclo curto e cultivada em várias épocas do ano, dependendo da região, vem estimulando o produtor para seu cultivo em rotação com outras espécies e em grandes áreas.

Além disso, o feijão é um dos alimentos básicos do povo brasileiro e integrante dos hábitos de consumo de grande parcela da população. No entanto, em vista do processo de urbanização ocorrido nas últimas décadas, do papel da mulher no mercado de trabalho, fora do lar, e da redução da disponibilidade de tempo para o preparo da alimentação da família, foram promovidas mudanças nos hábitos alimentares de parte da população, em busca de produtos com alta conveniência. Especificamente, verificou-se acentuada queda do consumo do produto feijão, sendo aos poucos substituído por outros alimentos de menores preços, como frango e macarrão e por iogurtes, cereais matinais, leite longa vida e bebidas esportivas, todos de rápido preparo (FERREIRA et al., 2002).

Assim, para reversão desse quadro, é de suma importância que se continue o processo de aumento da produtividade, principalmente pela melhoria do desempenho das cultivares. Esse fato, porém, isso deve estar associado a um produto com características culinárias e/ou tecnológicas desejadas pelos consumidores, destacando-se menor tempo para o cozimento, alta capacidade de hidratação, quantidade e também qualidade protéica (DuRIGAN et al., 1978; SgARBIERI, 1987; BRESSANI, 1989; LAM-SANCHES et al., 1990; CAzetTa et al., 1995).

Pelo seu papel fundamental como fonte protéica de origem vegetal, além de ser um dos principais constituintes da cesta básica nacional, o feijão é produto merecedor de especial atenção dos governantes, da pesquisa e de toda sua cadeia produtiva.

O objetivo deste trabalho foi avaliar o comportamento de cultivares de feijão do grupo comercial Carioca, identificando-se aqueles superiores quanto aos componentes da produção, produtividade de grãos e características tecnológicas.

\section{MATERIAL E MÉTODOS}

O experimento foi desenvolvido em área experimental localizada no município de São Manuel (SP), pertencente à Faculdade de Ciências Agronômicas - UNESP, Campus de Botucatu, com coordenadas geográficas $22^{\circ} 45^{\prime}$ latitude Sul e $48^{\circ} 34^{\prime}$ de longitude Oeste de Greenwich, com altitude de 750 metros em Latossolo Vermelho-Amarelo, com 80 e 20 $\mathrm{g} \mathrm{kg}^{-1}$ de areia e argila respectivamente.

A precipitação pluvial média anual do município é $1.433 \mathrm{~mm}$ e a umidade relativa média do ar é de $71 \%$, com temperatura média anual ao redor de $23{ }^{\circ} \mathrm{C}$. Os dados climáticos como temperatura máxima, mínima e média e precipitação pluvial, observadas durante o desenvolvimento do experimento, encontram-se na Figura 1.

A amostra de solo, coletada da área experimental, foi analisada de acordo com método proposto por RaIJ e QuAGGIO (1983), cujos resultados encontram-se na tabela 1.

Com o objetivo de elevar a saturação por bases a $70 \%$ foi aplicado em agosto de 2000 o equivalente a 1,5 toneladas por hectare de calcário dolomítico, com P.R.N.T. de 90\%, (AmBROSANO et al., 1997), incorporados posteriormente com uma aração e duas gradagens.

A adubação constou da aplicação de $240 \mathrm{~kg}$ $\mathrm{ha}^{-1}$ da fórmula comercial 8-28-16 + 0,4\% de B e Zn, nos sulcos de semeadura. A adubação de cobertura foi parcelada em duas aplicações, sendo a primeira com 15 e a segunda aos 35 dias após emergência, com $30 \mathrm{~kg} \mathrm{ha}^{-1}$ de N e $15 \mathrm{~kg} \mathrm{ha}^{-1}$ de $\mathrm{K}_{2} \mathrm{O}$, nas formas de uréia e cloreto de potássio, respectivamente, em cada aplicação.

A semeadura foi realizada na época "das águas" (PizAn et al., 1994), em 18 de setembro de 2000, utilizando-se 15 sementes por metro em espaçamento de $0,5 \mathrm{~m}$ entre linhas, para obter aproximadamente 240.000 plantas por hectare após o desbaste.

O delineamento experimental utilizado foi o de blocos casualizados, com 15 tratamentos, constituídos por cultivares de feijão do grupo comercial Carioca, com quatro repetições. Foram utilizadas as seguintes cultivares de feijão: Carioca, Pérola, IAC-Carioca SH, IAC-Carioca Eté, IAC-Carioca Pyatã, Carioca Precoce, IAC-Carioca Aruã, FT-Bonito, Rudá, Aporé, Princesa, IAPAR 14, IAPAR 80, IAPAR 81 e Porto Real.

A parcela experimental foi constituída por quatro linhas de $4 \mathrm{~m}$ de comprimento com espaçamento entre linhas de 0,5 metro. A área útil de cada parcela experimental foi composta pelas duas

Bragantia, Campinas, v.64, n.1, p.75-82, 2005 
Tabela 1. Características químicas de um Latossolo Vermelho-Amarelo na camada de 0-20 cm, em experimento de cultivares de feijoeiro, na época “das águas". São Manuel (SP), 2000

\begin{tabular}{|c|c|c|c|c|c|c|c|c|c|}
\hline $\mathrm{pH}$ & $\mathrm{MO}$ & $P_{\text {resina }}$ & $\mathrm{H}+\mathrm{Al}$ & $\mathrm{K}$ & $\mathrm{Ca}$ & $\mathrm{Mg}$ & SB & CTC & $\mathrm{V}$ \\
\hline $\mathrm{CaCl}_{2}$ & $\mathrm{~g} \mathrm{dm}^{-3}$ & $\mathrm{mg} \mathrm{dm}-^{3}$ & \multicolumn{6}{|c|}{$-\mathrm{mmol}_{\mathrm{c}} \mathrm{dm}^{-3}$} & $\%$ \\
\hline 4,6 & 20 & 8 & 25 & 1,1 & 10 & 4 & 15 & 40 & 38 \\
\hline
\end{tabular}

linhas centrais, desprezando-se 0,5 metro de cada extremidade.

As plantas daninhas foram controladas com a aplicação de trifluralim em pré-plantio incorporado, na dose de 1,0 $\mathrm{L} \mathrm{ha}^{-1} \mathrm{e}$, posteriormente, por meio de capinas manuais, sendo a primeira no início de desenvolvimento das plantas e a segunda, na fase final da cultura.

O controle das pragas e doenças foi feito pelo monitoramento da cultura, sendo necessárias duas aplicações, uma aos 30 e outra aos 51 dias após a semeadura. Os produtos utilizados foram Mancozeb + Oxicloreto de cobre $\left(750+450 \mathrm{~g} \mathrm{ha}^{-1}\right.$ de i.a. $)$, Metamidophos (600 $\mathrm{g} \mathrm{ha}^{-1}$ de i.a.) e Clorothalonil + Tiofanato metílico $\left(700+280 \mathrm{~g} \mathrm{ha}^{-1}\right.$ de i.a. $)$.

As irrigações foram efetuadas por um sistema de aspersão convencional, sendo utilizado turno de rega de cinco dias sempre que necessário, atendendo às necessidades do sistema solo-planta, principalmente nas fases de emergência das plântulas, de florescimento pleno e de enchimento de grãos.

Para avaliar os componentes da produção, ou seja, o número de vagens / planta, número de grãos / vagem e massa de cem grãos, coletaram-se ao acaso 10 plantas na área útil de cada parcela experimental.

A produtividade de grãos foi avaliada e transformada em $\mathrm{kg} \mathrm{ha}^{-1}$ na área útil de cada parcela experimental.
Quanto às características tecnológicas, determinou-se o teor de proteína bruta $(\mathrm{PB} \%)$ pela fórmula: $\mathrm{PB}=\mathrm{N}$ total $\times 6,25$, em que $\mathrm{N}$ total é igual ao teor de nitrogênio nos grãos, obtido na digestão sulfúrica (SARRUGE e HAAG, 1974).

O tempo para cozimento, em minutos, foi obtido para o feijão recém-colhido com o auxílio da máquina de Mattson, em que todas as partes do aparelho compreendidas pelos receptáculos e estiletes ficaram conservadas dentro de água quente, mantida em nível constante e com verificação periódica da temperatura, em média de $86^{\circ} \mathrm{C}$ (Durigan, 1979). Em vista do tempo de cozimento verificou-se o nível de resistência à cocção em cada cultivar de feijão, adotando-se a escala de Proctor e WATTS, 1987(Tabela 2).

A capacidade de hidratação foi determinada em amostras de $50 \mathrm{~g}$, colocadas em água destilada durante 12 horas. Nas primeiras 4 horas, o volume de água foi determinado a cada 30 minutos e nas 8 horas restantes, a cada uma hora. No fim do tempo previsto para a hidratação, a água foi totalmente drenada e os grãos pesados. Os grãos não hidratados, também denominados "duros", foram pesados separadamente e contados, sendo os resultados expressos em porcentagem (DuRIGAN, 1979). Durante a realização do teste, a temperatura média da água foi de $25{ }^{\circ} \mathrm{C}$.

A relação de hidratação foi determinada como a razão entre a massa após a hidratação e a massa inicial dos grãos.

Tabela 2. Valores médios de referência para o tempo de cozimento no feijão

\begin{tabular}{cc}
\hline Tempo para cozimento (minutos) & Nível de resistência ao cozimento \\
\hline $16<$ & muito suscetível \\
$16-20$ & suscetibilidade média \\
$21-28$ & resistência normal \\
$29-32$ & resistência média \\
$33-36$ & resistente \\
$36>$ & muito resistente \\
\hline
\end{tabular}


Os dados foram submetidos à análise de variância utilizando-se o teste $\mathrm{F}$ e para comparação de médias o teste de Tukey a $5 \%$ de probabilidade. Realizou-se também análise de regressão entre o tempo em horas e a capacidade de hidratação em $\mathrm{mL}$ a fim de avaliar o tempo necessário para a máxima hidratação dos grãos. Para a presença de grãos não hidratados e a relação de hidratação não foi realizada análise estatística.

\section{RESULTADOS E DISCUSSÃO}

Na cultura do feijão, a produtividade de grãos é altamente correlacionada com os componentes da produção, ou seja, número de vagens por planta, número de grãos por planta e massa de grãos (CostA e ZimmermanN, 1988; Coimbra et al., 1999). Dependendo das condições, alguns componentes da produção podem aumentar e outros diminuir, facilitando a manutenção da estabilidade da produtividade de grãos (Costa et al., 1983). Portanto, nas condições experimentais deste trabalho, ficou evidente a maior interferência da massa dos grãos (Tabela 3) na produtividade final das cultivares, sobretudo em Aporé e IAC-Carioca Eté, pois em ambas foram obtidos, para esse componente da produção, respectivamente, o maior e o menor valores.

A produtividade de grãos (Tabela 3) variou de $2.251 \mathrm{~kg} \mathrm{ha}^{-1}$ a $3.587 \mathrm{~kg} \mathrm{ha}^{-1}$, obtidos nas cultivares IAC-Carioca Eté e Aporé respectivamente. Destacaram-se com produtividade de grãos acima da média, ou seja, $3.046 \mathrm{~kg} \mathrm{ha}^{-1}$, as cultivares Aporé, Carioca Precoce, Rudá, IAPAR 81, FT-Bonito, IACCarioca SH, IAPAR 14, Carioca e Pérola. Esses resultados confirmam os relatos de ҮокоYАMA et al. (2000) e CARBOnEll et al. (2003) sobre a existência de cultivares de feijão com potencial produtivo acima de $3.000 \mathrm{~kg} \mathrm{ha}^{-1}$.

Outro aspecto importante na cultura do feijão é que, em vários trabalhos têm-se demonstrado a existência da interação genótipos e ambientes, ocorrendo diferenças no comportamento das linhagens e das cultivares em locais e também nos anos agrícolas e nas épocas de semeadura (RAMALHO et al., 1993; Duarte e Zimmermann, 1994; Piana et al., 1999; Carbonell e Pompeu, 2000). Carbonell et al. (2001) avaliaram a adaptabilidade e estabilidade de produção de 12 cultivares de feijão em 24 ambientes no Estado de São Paulo e obtiveram produtividade média de grãos, na época "das águas", de $2.515 \mathrm{~kg}$ $\mathrm{ha}^{-1}, 2.397 \mathrm{~kg} \mathrm{ha}^{-1}, 2.351 \mathrm{~kg} \mathrm{ha}^{-1}, 2.273 \mathrm{~kg} \mathrm{ha}^{-1}$ e 2.097

Bragantia, Campinas, v.64, n.1, p.75-82, 2005 $\mathrm{kg} \mathrm{ha}^{-1}$, para as cultivares FT-Bonito, Rudá, IACCarioca Eté, Pérola e IAC-Carioca SH respectivamente. Verificaram também que, quanto à adaptabilidade a ambientes específicos, as cultivares mais estáveis para a época "das águas" foram FT-Nobre, FT-Bonito e Rudá.

Outro fator que colaborou para o desempenho produtivo das cultivares foi a condição climática (Figura 1), associada aos tratos culturais adequados, como adubação, controle fitossanitário e irrigação. Verificou-se temperatura média em torno de $22{ }^{\circ} \mathrm{C}$, sendo favorável ao desenvolvimento vegetativo e reprodutivo do feijoeiro.

A temperatura máxima, na fase reprodutiva, poucas vezes foi maior do que $30^{\circ} \mathrm{C}$, não afetando os componentes da produção, pois segundo Didonet (2002) temperaturas de $37 / 25^{\circ} \mathrm{C}$ dia/noite interferem principalmente no número de grãos por vagem. Também na fase reprodutiva houve maior precipitação pluvial e quando necessário, fez-se uso de irrigação, o que favoreceu o desenvolvimento das cultivares de feijão. Sob estresse hídrico, o número de vagens por planta é o componente da produção mais afetado, havendo redução na produtividade de grãos (Guimarães et al., 1996; GoMes et al.; 2000).

O teor médio de proteína bruta nos grãos foi de $20,5 \%$ (Tabela 4 ), sendo inferior aos valores $22,7 \%$ e $25,4 \%$, verificados respectivamente por PÁRRAGA et al. (1981) e Pimentel et al. (1988) em duzentas cultivares e em vinte linhagens de feijão. Esses resultados corroboram com LAJOLO et al. (1996), que afirmaram haver variações no teor protéico em função do local de cultivo, de condições ambientais e principalmente pelo fator cultivar.

$\mathrm{Na}$ cultura do feijão, existem relatos do teor de proteína bruta ser influenciado negativamente pela produtividade de grãos (SGARBIERI, 1987; BRESSANI, 1989; PoMpeu, 1993). Nas condições experimentais deste trabalho esse fato foi observado somente nas cultivares Princesa e Carioca Precoce; na primeira obteve-se o maior teor de proteína bruta e, na segunda, produtividade de grãos acima de $3.500 \mathrm{~kg} \mathrm{ha}^{-1}$.

O tempo para cozimento variou de 33 a 45 minutos (Tabela 4), valores especificamente obtidos nas cultivares IAPAR 80 e Carioca Precoce respectivamente. Essa diferença de 12 minutos é favorável e vantajosa para a primeira cultivar pela economia de tempo e de consumo de gás durante o processo de cocção.

Comparando-se os resultados obtidos do tempo para cozimento com os níveis de resistência à cocção (Tabela 4), verifica-se que as cultivares Carioca, IAC-Carioca Eté, IAC-Carioca Pyatã, FT-Bonito, 
Tabela 3. Componentes da produção e produtividade de grãos de feijão, de diferentes cultivares, na época "das águas". São Manuel (SP), 2000

\begin{tabular}{|c|c|c|c|c|}
\hline Cultivares & Vagens/ planta & Grãos/ vagem & Massa de 100 grãos & Produtividade de grãos \\
\hline & . & 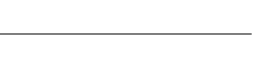 & $\mathrm{g}$ & $\mathrm{kg} \mathrm{ha}^{-1}$ \\
\hline Carioca & 18,5 & $5,7 \mathrm{ab}$ & $29,3 \mathrm{abc}$ & 3.127 \\
\hline Pérola & 14,0 & $5,5 \mathrm{ab}$ & $28,5 \mathrm{abcd}$ & 3.074 \\
\hline IAC Carioca & 22,0 & 6,0 a & $25,3 \mathrm{~cd}$ & 3.334 \\
\hline IAC Carioca Eté & 18,7 & $5,3 \mathrm{ab}$ & $23,0 \mathrm{~d}$ & 2.251 \\
\hline IAC Carioca Pyatã & 14,5 & $5,0 \mathrm{ab}$ & 27,3 abcd & 2.413 \\
\hline Carioca Precoce & 17,7 & $5,7 \mathrm{ab}$ & $28,7 \mathrm{abcd}$ & 3.518 \\
\hline IAC Carioca Aruã & 20,3 & $5,0 \mathrm{ab}$ & 28,3 abcd & 2.630 \\
\hline FT Bonito & 17,5 & $5,7 \mathrm{ab}$ & 28,6 abcd & 3.387 \\
\hline Rudá & 22,3 & $5,7 \mathrm{ab}$ & $24,7 \mathrm{~cd}$ & 3.512 \\
\hline Aporé & 15,7 & $5,5 \mathrm{ab}$ & 32,4 a & 3.587 \\
\hline Princesa & 19,3 & $4,7 \mathrm{~b}$ & $26,2 \mathrm{bcd}$ & 2.906 \\
\hline IAPAR 14 & 19,7 & $5,0 \mathrm{ab}$ & $28,2 \mathrm{abcd}$ & 3.268 \\
\hline IAPAR 80 & 17,3 & $5,3 \mathrm{ab}$ & $25,3 \mathrm{abcd}$ & 2.658 \\
\hline IAPAR 81 & 22,3 & $5,3 \mathrm{ab}$ & 28,6 abcd & 3.400 \\
\hline Porto Real & 15,5 & $5,0 \mathrm{ab}$ & $31,5 \mathrm{ab}$ & 2.757 \\
\hline Média & 18,4 & 5,3 & 27,9 & 3046 \\
\hline F para cultivares & $1,66^{\mathrm{ns}}$ & $2,50 *$ & $4,12^{* *}$ & $2,36^{\mathrm{ns}}$ \\
\hline C.V. (\%) & 22,7 & 8,6 & 8,5 & 18,2 \\
\hline D.M.S. (5\%) & 4,07 & 1,17 & 6,06 & 1.415 \\
\hline
\end{tabular}

Médias seguidas de mesma letra na vertical não diferem entre si pelo teste de Tukey a $5 \%$. $\mathrm{ns}=$ não significativo; ${ }^{*}{ }^{* *}=$ significativo a $5 \%$ e a $1 \%$ respectivamente.

\section{Dias após semeadura}

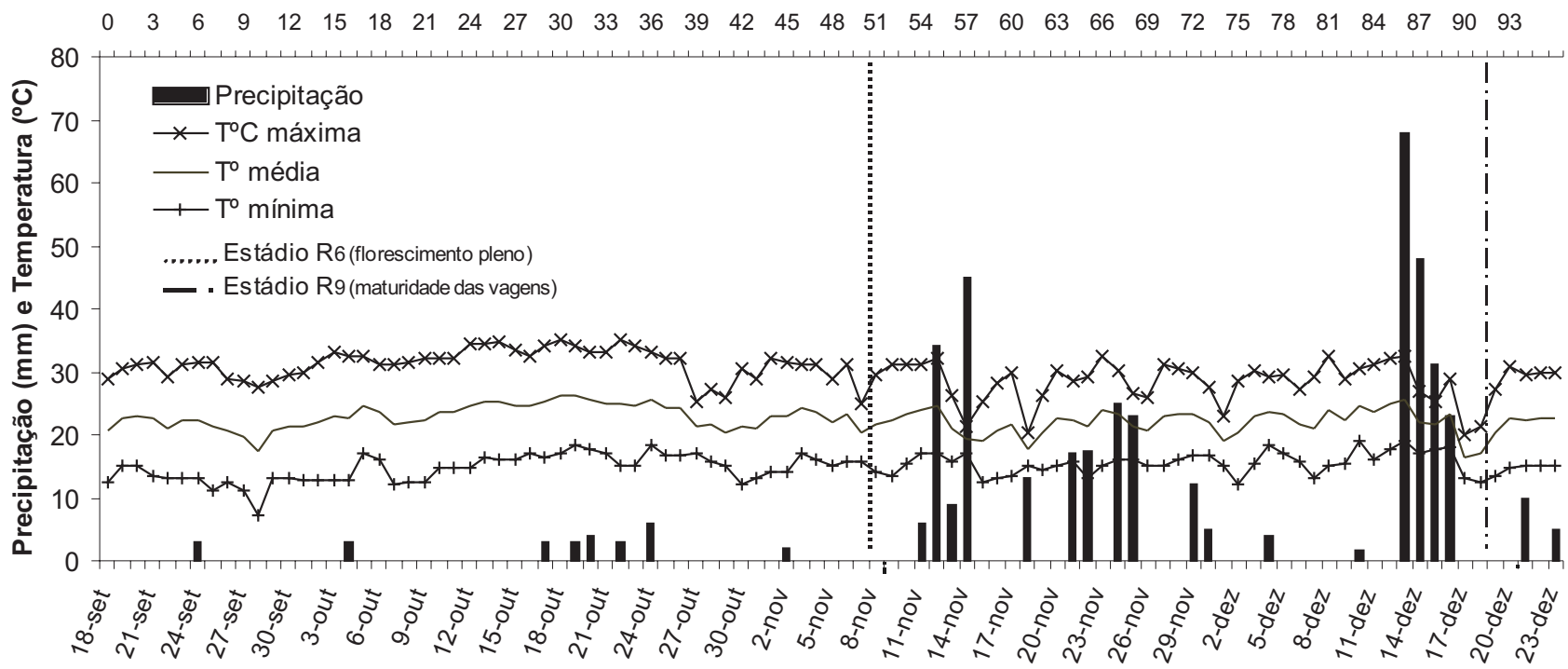

Data

Figura 1. Temperaturas máxima, média e mínima e precipitação pluvial determinadas durante experimentação de cultivares de feijoeiro na época “das águas". São Manuel (SP), 2000. 
Tabela 4. Teor de proteína bruta, tempo para cozimento e grãos duros de cultivares de feijão, cultivados na época "das águas". São Manuel (SP), 2000

\begin{tabular}{|c|c|c|c|}
\hline Cultivares & Teor de proteína bruta & Tempo para cozimento & Grãos duros \\
\hline & $\%$ & minutos & $\%$ \\
\hline Carioca & $21,4 \mathrm{ab}$ & 35 & 0 \\
\hline Pérola & $21,0 \mathrm{ab}$ & 37 & 1,2 \\
\hline IAC Carioca & $20,5 \mathrm{ab}$ & 42 & 0 \\
\hline IAC Carioca Eté & $19,8 \mathrm{ab}$ & 34 & 0,6 \\
\hline IAC Carioca Pyatã & $20,5 \mathrm{ab}$ & 36 & 0,1 \\
\hline Carioca Precoce & $19,1 \mathrm{~b}$ & 45 & 0 \\
\hline IAC Carioca Aruã & $19,6 \mathrm{ab}$ & 37 & 0 \\
\hline FT Bonito & $20,6 \mathrm{ab}$ & 36 & 0 \\
\hline Rudá & $19,5 \mathrm{ab}$ & 39 & 0 \\
\hline Aporé & $20,1 \mathrm{ab}$ & 37 & 0,1 \\
\hline Princesa & 23,5 a & 35 & 0,1 \\
\hline IAPAR 14 & $19,5 \mathrm{ab}$ & 35 & 0 \\
\hline IAPAR 80 & $20,6 \mathrm{ab}$ & 33 & 0 \\
\hline IAPAR 81 & $21,2 \mathrm{ab}$ & 35 & 0 \\
\hline Porto Real & $21,4 \mathrm{ab}$ & 35 & 0 \\
\hline Média & 20,5 & 37 & 0,1 \\
\hline F para cultivares & $1,26^{*}$ & $1,31^{\mathrm{ns}}$ & - \\
\hline C.V. $(\%)$ & 8,2 & 15,2 & - \\
\hline D.M.S. (5\%) & 4,26 & 14,25 & - \\
\hline
\end{tabular}

Médias seguidas de mesma letra na vertical não diferem entre si pelo teste de Tukey a $5 \%$. ns $=$ não significativo, ${ }^{*}=$ significativo a $5 \%$.

Princesa, IAPAR 14, IAPAR 80, IAPAR 81 e Porto Real, enquadram-se como resistentes e Pérola, IAC-Carioca SH, Carioca Precoce, IAC-Carioca Aruã, Rudá e Aporé como muito resistentes. Apesar do tempo para cozimento em feijão ser influenciado pela interação genótipos e ambientes (Durigan et al., 1978; Pimentel et al., 1988; Bressani, 1989; VieIra et al., 1989; LamSANCHES et al., 1990; CAZETTA et al., 1995), deve-se considerar na discussão dos resultados obtidos e, conseqüentemente, na comparação com a literatura disponível, outros fatores como período transcorrido da colheita até a avaliação e as condições de armazenamento (SARTORI, 1996; CHIARADIA e GoMES, 1997) e, principalmente, o sistema e a temperatura da água no processo de cocção.

Quanto à presença de grãos denominados duros, sem a capacidade de absorver água, ou seja, o fenômeno de tegumento impermeável à água (Tabela 4), verifica-se que, em apenas cinco cultivares, constatou-se tal característica, variável de 0,1 a 1,2\%, sendo baixa a ocorrência. Portanto, as cultivares de feijão apresentaram comportamento favorável para essa característica, decorrentes dos trabalhos de melhoramento genético, conforme descreveram MORENO e LoPEZ (1992).
Conforme as equações de regressão entre o tempo para hidratação e a quantidade de água absorvida (Tabela 5), o tempo para a máxima hidratação variou de $8 \mathrm{~h} 10 \mathrm{~min}$ a $12 \mathrm{~h} 1 \mathrm{~min}$ nas cultivares IAC-Carioca Aruã e IAC-Carioca Pyatã. Portanto, houve diferença de 3 horas e 51 minutos, podendo ser considerado um valor elevado. No entanto, como geralmente os grãos de feijão são deixados em maceração na noite anterior ao preparo, por um período de aproximadamente 12 horas, observou-se comportamento satisfatório para a completa embebição nas cultivares. Observou-se também variação de 1,85 a 1,99 na relação de hidratação, após 12 horas de maceração, nas cultivares Carioca Precoce e Pérola (Tabela 5), respectivamente, muito próximo de 2,0. Esse fato significa que, nos grãos das cultivares de feijão, foi absorvido a sua própria massa de água, tendo em média, relação de hidratação de 1,92. Portanto, para essa característica, foram constatados resultados adequados nas cultivares de feijão, concordando com Durigan et al. (1978), LAm-SANCHES et al. (1990) e CAzetta et al. (1995).

\section{CONCLUSÕES}


Tabela 5. Regressão entre o tempo para hidratação e quantidade de água absorvida pelos grãos e relação de hidratação de cultivares de feijão, cultivados na época "das águas". São Manuel (SP), 2000

\begin{tabular}{|c|c|c|c|c|c|}
\hline \multirow[t]{2}{*}{ Cultivares } & \multicolumn{2}{|c|}{ Equação de Regressão } & \multirow[t]{2}{*}{$\mathrm{R}^{2}$} & \multirow{2}{*}{$\begin{array}{c}\text { Tempo para } \\
\text { hidratação máxima } \\
\text { horas }\end{array}$} & \multirow[t]{2}{*}{$\begin{array}{l}\text { Relação de } \\
\text { hidratação }\end{array}$} \\
\hline & & & & & \\
\hline Carioca & $Y=8,9874+8,6360 X$ & $-0,4996 X^{2}$ & 0,9119 & $8: 38$ & 1,86 \\
\hline Pérola & $Y=2,3586+9,9044 X$ & $-0,5076 X^{2}$ & 0,9872 & $9: 46$ & 1,99 \\
\hline IAC Carioca & $Y=2,2294+9,3147 X$ & $-0,4554 X^{2}$ & 0,9959 & $10: 14$ & 1,96 \\
\hline IAC Carioca Eté & $Y=3,5181+9,4563 X$ & $-0,4956 X^{2}$ & 0,9858 & $9: 32$ & 1,93 \\
\hline IAC Carioca Pyatã & $Y=-2,6606+8,2749 X$ & $-0,3441 X^{2}$ & 0,9937 & $12: 01$ & 1,93 \\
\hline Carioca Precoce & $Y=9,8130+8,1551 X$ & $-0,4678 X^{2}$ & 0,9150 & $8: 43$ & 1,85 \\
\hline IAC Carioca Aruã & $Y=14,4299+8,2631 X$ & $-0,5055 X^{2}$ & 0,8107 & $8: 10$ & 1,90 \\
\hline FT-Bonito & $Y=-0,9903+9,4796 X$ & $-0,4552 X^{2}$ & 0,9956 & $10: 25$ & 1,95 \\
\hline Rudá & $Y=2,9699+9,1948 X$ & $-0,4895 X^{2}$ & 0,9701 & $9: 23$ & 1,88 \\
\hline Aporé & $Y=6,1822+10,1063 X$ & $-0,5674 X^{2}$ & 0,9580 & $8: 55$ & 1,97 \\
\hline Princesa & $Y=0,7874+7,7789 X$ & $-0,3459 X^{2}$ & 0,9928 & $11: 14$ & 1,89 \\
\hline IAPAR 14 & $Y=5,6862+9,1849 X$ & $-0,5172 X^{2}$ & 0,9573 & $8: 53$ & 1,89 \\
\hline IAPAR 80 & $Y=10,6043+7,5172 X$ & $-0,4180 X^{2}$ & 0,8994 & $8: 59$ & 1,87 \\
\hline IAPAR 81 & $Y=5,9977+9,5677 X$ & $-0,5529 X^{2}$ & 0,9390 & $8: 39$ & 1,90 \\
\hline Porto Real & $Y=-3,2607+10,7344 X$ & $-0,5544 X^{2}$ & 0,9837 & 9:41 & 1,95 \\
\hline Média & - & & - & $9: 24$ & 1,92 \\
\hline
\end{tabular}

$\mathrm{X}=$ tempo para hidratação (horas); $\mathrm{Y}=$ quantidade de água absorvida $(\mathrm{mL})$.

1. A massa de cem grãos e o número de grãos por vagem são os componentes de maior influência na produtividade de grãos de cultivares de feijão.

2. As cultivares Aporé, Carioca Precoce e Rudá destacam-se com produtividade de grãos acima de $3.500 \mathrm{~kg} \mathrm{ha}^{-1}$

3. As características tecnológicas dos grãos das cultivares Carioca, IAPAR 80 e IAPAR 81, são superiores.

\section{REFERÊNCIAS}

AMBROSANO, E.J.; WUTKE, E.B.; BULISANI, E.A.; CANTARELLA, H. Feijão. In: RAIJ, B. van; CANTARELA, H.; QUAGGIO, J.A.; FURLANI, A.M.C. Recomendações de adubação e calagem para o Estado de São Paulo. 2.ed. Campinas: IAC, 1997. p.194-195. (Boletim Técnico 100)

BRESSANI, R. Revision sobre la calidad del grano de frijol. Archivos Latinoamericanos de Nutricion, Guatemala, v.39, p.419-442, 1989.

CARBONELL, S.A.M.; AZEVEDO FILHO, J.A.; DIAS, L.A.S.; GONÇALVES, C.; ANTONIO, C.B. Adaptabilidade e estabili- dade de produção de cultivares e linhagens de feijoeiro no Estado de São Paulo. Bragantia, Campinas, v.60, n.2, p.69-77, 2001.

CARBONELL, S.A.M.; ITO, M.F.; AZEVEDO FILHO, J.A.; SARTORI, J.A. Cultivares comerciais de feijoeiro para o Estado de São Paulo: Características e melhoramento. In: CASTRO, J.L.; ITO, M.F. (Coord.). DIA DE CAMPO DE FEIJÃO, 19, 2003, Capão Bonito. Campinas: Instituto Agronômico, 2003. p.5-27 (Documentos IAC, 71).

CARBONELL, S.A.M.; POMPEU, A.S. Estabilidade fenotípica de linhagens de feijoeiro em três épocas de plantio no Estado de São Paulo. Pesquisa Agropecuária Brasileira, Brasília, v.35, n.2, p.321-329, 2000.

CAZETTA, J.O.; KANESHIRO, M.A.B.; FALEIROS, R.R.S.; DURIGAN, J.F. Comparação de aspectos químicos e tecnológicos de grãos verdes e maduros de guandu com os de feijão e ervilha. Alimentos e Nutrição, São Paulo, v.6, p.39-53, 1995.

CHIARADIA, A.C.N.; GOMES, J.C. Feijão: química, nutrição e tecnologia. Viçosa: Universidade Federal de Viçosa, 1997. 180p.

COIMBRA, J.L.M.; GUIDOLIN, A.F.; CARVALHO, F.I.F.; COIMBRA, S.M.M.; MARCHIORO, V.S. Análise de trilha I: Análise do rendimento de grãos e seus componentes. Ciência Rural, Santa Maria, v.29, n.2, p.213-218, 1999.

COSTA, J.C.G.; ZIMMERMANN, M.J.O. Melhoramento genético. In: ZIMMERMANN, M.J.O.; ROCHA, M.; YAMADA, T. 
(Ed.). A cultura do feijoeiro: fatores que afetam a produtividade. Piracicaba: Potafós . 1988. p. 229-245.

COSTA, J.G.C.; KOHASHI-SHIBATA, J.; COLIN, S.M. Plasticidade no feijoeiro comum. Pesquisa Agropecuária Brasileira, Brasília, v.18, n.2, p.159-167, 1983.

DIDONET, A.D. Respostas da cultivar de feijoeiro comum Pérola ao choque térmico com altas temperaturas. Santo Antônio de Goiás: Embrapa Arroz e Feijão, 2002. 3p. (Comunicado Técnico, 39).

DUARTE, J.B.; ZIMMERMANN, M.J.O. Adaptabilidade e estabilidade de rendimento de genótipos de feijoeiro comum. Pesquisa Agropecuária Brasileira, Brasília, v.29, n.1, p.25-32, 1994.

DURIGAN, J.F.; FALEIROS, R.R.S.; LAM-SANCHES, A. Determinação das características tecnológicas e nutricionais de diversas variedades de feijão (Phaseolus vulgaris, L.). I. Características Tecnológicas. Científica, São Paulo, v.6, n.2, p.209-213, 1978.

DURIGAN, J.F. Influência do tempo e das condições de estocagem sobre as propriedades químicas, físico-mecânicas e nutricionais do feijão mulatinho (Phaseolus vulgaris L.). Campinas, 1979. 81 f. Dissertação (Mestrado em Ciência de Alimentos) - Universidade de Campinas, Campinas, 1979.

FERREIRA, C.M.; DEL PELOSO, M.J.; FARIA, L.C. Feijão na economia nacional. Santo Antônio de Goiás: Embrapa Arroz e Feijão, 2002. 47p. (Documentos, 135)

GOMES, A.A.; ARAÚJO, A.P.; ROSSIELLO, R.O.P.; PIMENTEL, C. Acumulação de biomassa, características fisiológicas e rendimento de grãos em cultivares de feijoeiro irrigado e sob sequeiro. Pesquisa Agropecuária Brasileira, Brasília, v.35, n.10, p.1927-1937, 2000.

GUIMARÃES, C.M.; STONE, L.F.; BRUNINI, O. Adaptabilidade do feijoeiro (Phaseolus vulgaris L.) à seca. II. Produtividade e componentes agronômicos. Pesquisa Agropecuária Brasileira, Brasília, v.31, n.7, p.481-488, 1996.

LAJOLO, F.M.; GENOVESE, M.I.; MENEZES, E.W. Qualidade nutricional. In: ARAUJO, R.S.; RAVA, C.A.; STONE, L.F.; ZIMMERMANN, M.J.O. (Coord.) Cultura do feijoeiro comum no Brasil. Piracicaba: POTAFOS, p.23-56, 1996.

LAM-SANCHEZ, A.; DURIGAN J.F.; CAMPOS, S.L.; SILVESTRE, S.R.; PEDROSO, P.A.C.; BANZATTO, D.A. Efeitos da época de semeadura sobre a composição química e características físico-químicas de grãos de Phaseolus vulgaris L., Phaseolus angularis (Wild) Wright e Vigna unguiculata (L.) Walp. Alimentos e Nutrição, São Paulo, v.2, p. 35-44, 1990.

MORENO, C.R.; LOPEZ, O.P. Endurecimento del frijol común. Cuadernos del Nutricion, México, v.15, n.2, p.17-32, 1992.

PÁRRAGA, M.S.; JUNQUEIRA NETTO, A.; PEREIRA, P.; BUENO, L.C.S.; PENONI, J.S. Avaliação do conteúdo de proteína total de duzentas cultivares de feijão (Phaseolus vulgaris L.) visando seu melhoramento genético. Ciência e Prática, Lavras, v.5, n.1, p.07-17, 1981.

PIANA, C.F.B.; ANTUNES, I.F.; SILVA, J.G.C.; SILVEIRA, E..
Adaptabilidade e estabilidade do rendimento de grãos de genótipos de feijão. Pesquisa Agropecuária Brasileira, Brasília, v.34, n.4, p.553-564, 1999.

PIMENTEL, M.L.; MIRANDA, P.; COSTA, A.F.; MIRANDA, A.B. Estudo nutricional de linhagens de feijão comum (Phaseolus vulgaris L.). Revista Brasileira de Sementes, Brasília, v.10, n.2, p.55-65, 1988.

PIZAN, N.R.; BULISANI, E.A.; BERTI, A.J. Feijão: Zoneamento ecológico e épocas de semeadura para o Estado de São Paulo. Campinas: Coordenadoria de Assistência Técnica Integral, 1994. 19p. (Boletim Técnico, 218).

POMPEU, A.S. Feijão. In: FURLANI, A.M.C.; VIÉGAS, G.P. (Eds.). O Melhoramento de Plantas no Instituto Agronômico. Campinas: Instituto Agronômico, 1993. p.111-155.

PROCTOR, J.R.; WATTS, B.M. Development of a modified Mattson Bean Cooker procedure base don sensory panel cookability evaluation. Canadian Institute of Food Science and Technology Journal, Toronto, v.20, n.1, p.9-14, 1987.

RAIJ, B.van.; QUAGGIO, A.J. Métodos de análise do solo para fins de fertilidade. Campinas: Instituto Agronômico, 1983, 31p. (Boletim Técnico, 81)

RAMALHO, M.A.P.; ABREU, A.F.B.; SANTOS, J.B. Desempenho de progênies precoces de feijoeiro (Phaseolus vulgaris L.) em diferentes locais e épocas de plantio. Revista Ceres, Viçosa, v. 40, n.229, p.272-280, 1993.

SARTORI, M.R. Armazenamento. In: ARAUJO, R.S.; RAVA, C.A.; STONE, L.F. ZIMMERMANN, M.J.O. (Coord.). A cultura do feijoeiro comum no Brasil. Piracicaba: POTAFOS, 1996. p.543-558.

SARRUGE, J.R.; HAAG, H.P. Análises químicas em plantas. Piracicaba: ESALQ, 1974. 56p. (Mimeografado).

SGARBIERI, V.C. Composição e valor nutritivo do feijão (Phaseolus vulgaris L.). In: BULISANI, E.A.(Coord.). Feijão: Fatores de produção e qualidade. Campinas: Fundação Cargill, 1987. p.257-316.

VIEIRA, R.F.; ROMEIRO, E.M.C.; SOUZA, L.R.P.; DONZELLI, M.F.; VIEIRA, V. Tempo de cocção, rendimento alimentar e aceitabilidade de feijões secos dos gêneros Vigna e Phaseolus. Revista Ceres, Viçosa, v.36, p.525-37, 1989.

YOKOYAMA, L.P.; WETZEL, C.T.; VIEIRA, E.H.N.; PEREIRA, G.V. Sementes de feijão: Produção, uso e comercialização. In: VIEIRA, E.H.N.; RAVA, C.A. (Ed.). Sementes de feijão: Produção e tecnologia. Santo Antônio de Goiás: Embrapa Arroz e Feijão, 2000. p.249-270.

ZIMMERMANN, M.J.O.; CARNEIRO, J.E.S.; DEL PELOSO, M.J.; COSTA, J.G.C.; RAVA, C.A.; SARTORATO, A.; PEREIRA, P.A.A. Melhoramento genético e cultivares. In: ARAUJO, R.S.; RAVA, C.A.; STONE, L.F.; ZIMMERMANN, M.J.O. (Coords.). Cultura do feijoeiro comum no Brasil. Piracicaba: POTAFOS, 1996, p.223-273. 